\title{
CONDIÇÕES DO TRABALHO DOCENTE E DE TUTORIA NA EAD: FRAGILIZAÇÃO E PRECARIEDADE
}

\section{TEACHING AND TUTORING CONDITIONS IN DISTANCE EDUCATION: FRAGILIZATION AND PRECARIOUSNESS}

\section{CONDICIONES DE TRABAJO DOCENTE Y TUTORÍA EN EAD: FRAGILIZACIÓN Y PRECARIEDAD}

Juliana Cordeiro Soares Branco ${ }^{1}$ Daniela Oliveira Ramos dos Passos ${ }^{2}$

\begin{abstract}
Resumo: O presente texto visa abordar aspectos relacionados ao trabalho docente na Educação a Distância-EaD. Para tal apresenta estudo bibliográfico e documental sobre o tema, analisa a política Universidade Aberta do Brasil-UAB na perspectiva do trabalho de tutoria e como na contemporaneidade o capitalismo vem alterando a composição da classe trabalhadora, inclusive no âmbito educacional. Como considerações, entendemos que as experiências em EaD seja algo diverso, amplo e com uma multiplicidade de fatores que são positivos, como levar educação a lugares longínquos e de difícil acesso às instituições educacionais presenciais. Porém, o que chamamos a atenção é para a precariedade do trabalho docente e de tutoria que tem aspectos perversos de contratação, fragilização ou inexistência de vínculos empregatícios, além da sobrecarga de trabalho.
\end{abstract}

Palavras-chave: Trabalho docente, Tutoria, Educação a distância.

\begin{abstract}
This work aims to address aspects related to teaching Distance Education. To this end, it presents a bibliographical and documentary study on the subject, analyzes the Open University of Brazil (Universidade Aberta do Brasil - UAB) public policy from the perspective of tutoring work and how capitalism has been changing the composition of the working class, including in the educational sphere. From the acknowledgement that experiences with distance education are diverse, broad and with multiple positive factors, such as providing education to remote and inaccessible areas for on-site educational institutions, we call attention to the precarious working conditions of teachers and tutors, including perverse hiring practices, the weakening or inexistence of job security, in addition to work overload.
\end{abstract}

Keyword: Teaching work, Tutoring, Distance education

\footnotetext{
${ }^{1}$ Universidade do Estado de Minas Gerais. Belo Horizonte, Minas Gerais, Brasil.

${ }^{2}$ Universidade do Estado de Minas Gerais. Belo Horizonte, Minas Gerais, Brasil.
} 
Resumen: Este texto tiene como objetivo abordar aspectos relacionados con el trabajo docente en educación a distancia-EaD. Con este fin, presenta un estudio bibliográfico y documental sobre el tema, analiza la política de la Universidade Aberta do Brasil-UAB desde la perspectiva del trabajo de tutoría y cómo en la actualidad el capitalismo ha estado cambiando la composición de la clase trabajadora, incluso en el ámbito educativo. Como consideraciones, entendemos que las experiencias de aprendizaje a distancia son algo diverso, amplio y con una multiplicidad de factores que son positivos, como llevar la educación a lugares distantes e instituciones educativas en persona de difícil acceso. Sin embargo, llamamos la atención sobre la precariedad del trabajo de enseñanza y tutoría, que tiene aspectos perversos de contratación, debilitamiento o falta de empleo, además de la sobrecarga de trabajo.

Palabras clave: Trabajo docente, Tutoría, Educación a distancia.

\section{INTRODUÇÃO: PROCESSO HISTÓRICO DO SURGIMENTO DA EAD}

A Educação a Distância (EaD) é uma modalidade de ensino que tem crescido, mundialmente, nas últimas décadas. Impulsionada pelos avanços das Tecnologias Digitais de Informação e Comunicação (TDICS), a área tem proporcionado novos processos de ensino-aprendizagem; mudando, inclusive, os papéis de docência e discência, bem como a forma com a qual as relações de trabalho se estabelecem.

O presente texto visa discutir aspectos relacionados à profissão docente na Educação a Distância (EaD), em contexto nacional. O artigo, portanto, através de um estudo pautado em análises da literatura científica sobre os campos da educação e de documentos oficiais - que representam as políticas públicas educacionais do Brasil -, tenta responder as seguintes questões: (1) como é o trabalho docente na EaD?; (2) Quem é este docente?; e (3) Quais são as suas condições objetivas de trabalho?. Antes, porém, é necessário contextualizar alguns aspectos da EaD e como o capitalismo contemporâneo vem alterando, globalmente, a composição da classe trabalhadora.

Desse modo, especificamente sobre a Educação a Distância, em um levantamento histórico, Nunes (2009) salienta que a EaD teve início com o professor Caleb Philips, em 1728, por meio do curso profissionalizante de taquigrafia, que utilizava material impresso (Gazette de Boston - Estados Unidos da América (EUA)) enviado por correspondência. Saraiva (1996), todavia, menciona que o advento da EaD nestes moldes, deu-se a partir do século XIX, por iniciativa de Charles Toussaint e Gustav Langenscheidt, em 1856, Berlim, com a criação da primeira escola de línguas por correspondência. A autora, ainda, aponta que tal modalidade de ensino foi instituída, nos EUA, apenas em 1873, com a fundação, em Boston, da Society to Encourage Study at Home. 
Para Palhares (2009), independentemente de sua origem, o ensino por correspondência é o primeiro e mais longo modelo (em termos geracionais) de EaD. Peters (2006, p. 49), nesse contexto, ressalta que "a correspondência era, na época, o meio de comunicação mais importante e que, portanto, se oferecia como solução para vencer a distância entre docentes e discentes". Todavia, percebe-se que, apesar de ser um importante meio de educação, o ensino por correspondência apresentava dificuldades de interação entre os sujeitos envolvidos no processo de ensino e aprendizagem, tendendo a ser uma comunicação unilateral, centrada no/a professor/a.

Em sequência, com o desenvolvimento tecnológico, surgiu a capacitação por rádio, que ganhou destaque devido à sua abrangência e acessibilidade. "Pelo seu alcance em todos os segmentos sociais, ampla cobertura geográfica e baixo custo do aparelho, o rádio oferece possibilidades para a EAD no desenvolvimento de programas de educação formal e não formal" (BIANCO, 2009, p. 57). Nesse sentido, o rádio é considerado um importante meio de ensino a distância, uma vez que a ferramenta-mediadora privilegiava interações e trocas, em detrimento da mera transmissão de conteúdos.

Ademais, segundo Formiga (2009), a partir da segunda metade do século XX, com a disseminação da televisão (TV), programas voltados para a educação passaram a ser elaborados com imagens, dramatização, textos, sons, etc. A TV, que aos poucos chegou à casa da maioria da população, passou, então, a ser um importante meio de ensino a distância.

Já no final do século XX, conforme o mesmo autor, outro aparelho revolucionou o ensino: o computador. Primeiramente, só a máquina, sem ligação à rede - em que era possível estudar e fazer cursos utilizando o Compact Disc Read-Only Memory (CD-ROM), desenvolvido, em 1985, pelas marcas Sony e Philips. O recurso possibilitava, em síntese, que os idealizadores das atividades armazenassem dados com grande capacidade - sons, imagens, e textos -; sendo esses, posteriormente, consultados como material didático, por estudantes e cursistas.

Enquanto isso, a passos lentos, ocorria o vertiginoso avanço da internet: "em 1968/69 por intermédio da Administração dos Projetos de Pesquisa Avançada do Departamento de Defesa dos Estados Unidos (ARPA), estabeleceu-se o embrião da atual internet: a Arpanet foi a primeira rede de computadores a longa distância" (GOUVÊA; OLIVEIRA, 2006, p. 24). A ferramenta, desenvolvida e popularizada em pouco mais de vinte anos - no intervalo de 1968 e 1990 -, inicialmente, era um privilégio restrito às áreas acadêmicas e militares. 
A partir da década de 1990, no entanto, os grandes avanços digitais permitiram e difundiram o acesso às máquinas e às tecnologias comunicativas, telemáticas, redes virtuais, Tecnologias da Informação e Comunicação (TICs), etc. As últimas, também denominadas como Tecnologias Digitais de Informação e Comunicação (TDICS), "podem gerar condições para um aprendizado mais interativo, por meio de caminhos não lineares, em que o estudante determina seu ritmo, sua velocidade, seus percursos" (NUNES, 2009, p. 7).

Nesse modelo, portanto, visualizam-se maiores possibilidades de comunicação: em uma conversação virtual, pela rede, todos podem trocar ideias, experiências e conhecimentos. "As redes se tornaram a forma organizacional predominante em todos os campos da atividade humana [...]. As tecnologias de comunicação construíram a virtualidade como uma dimensão fundamental de nossa realidade" (CASTELLS, 2011, p. XXXIX - XXX).

A metodologia educacional em TICs, entretanto, não deve se restringir ao envio de materiais didáticos via web (reprodução do ensino por correspondência), ou à discussão dos estudos desenvolvidos por cada participante. Isso, pois, nessa abordagem, a tecnologia deve incentivar a busca de conhecimento, a investigação e a construção de projetos:

A integração potencial de texto, imagens e sons no mesmo sistema - interagindo a partir de pontos múltiplos, no tempo escolhido (real ou atrasado) em uma rede global, em condições de acesso aberto e de preço acessível - muda de forma fundamental o caráter da comunicação. E a comunicação, decididamente, molda a cultura porque, como afirma Postman, nós não vemos [...] a realidade [...] como ela é, mas como são nossas linguagens. E nossas linguagens são nossos meios de comunicação. Nossos meios de comunicação são nossas metáforas. Nossas metáforas criam o conteúdo de nossa cultura. (CASTELLS, 2011, p. 414).

Os avanços mencionados, assim, permitem-nos pensar e refletir sobre a educação, o uso da EaD e das tecnologias digitais, de modo a potencializar esses recursos em prol de um ensino objetivamente eficiente. Nesse contexto, a EaD ganha mais espaço a medida em que oferece alternativas educacionais que podem democratizar o ensino, em termos de novas oportunidades de acesso e permanência.

Ademais, é necessário buscar, constantemente, uma educação de qualidade, com material e infra-estrutura adequados; docentes capacitados; e condições de trabalho apropriadas, seja em contexto presencial ou a distância. Frisa-se isso, pois, a oferta de formações precárias, sem o cumprimento efetivo de seus objetivos educacionais, torna-se pseudoformações, que podem intensificar a exclusão social, em detrimento da inclusão. 
Finalmente, aliado ao histórico do surgimento e expansão da EaD, é preciso, também, salientar as transformações ocorridas no capitalismo, pós-década de 1990. Estas, impulsionadas pela nova divisão do internacional do trabalho, proporcionaram a redução do proletariado industrial e o avanço de empregos nos setores de serviços, ampliando os trabalhos chamados de "teletrabalho" ou "home office". A ocupação fora dos espaços laborais, nesse sentido:

[...] pode trazer vantagens, como economia de tempo em deslocamentos, permitindo uma melhor divisão entre trabalho produtivo e reprodutivo, dentre outros pontos positivos. Mas com frequência é, também uma porta de entrada para a eliminação dos direitos do trabalho e da seguridade social paga pelas empresas, além de permitir a intensificação da dupla jornada de trabalho, tanto produtivo quanto o reprodutivo (sobretudo no caso das mulheres). Outra consequência negativa é a de incentivar o trabalho isolado, sem sociabilidade, desprovido do convívio social e coletivo e sem representação sindical (ANTUNES, 2018, p. 37).

Desse modo, observa-se que tal situação vem impondo sua tríade perversa e destrutiva em relação ao trabalho: a terceirização, informalidade e flexibilidade.

De acordo com Medeiros e Passos (2019), o final do século XX foi marcado por transformações no modelo de organização da produção taylorista/fordista ${ }^{3}$ - predominante nos países industrializados -, que o alteraram a uma sistemática de acumulação flexível. Tais mudanças foram causadas, principalmente, pela crise do capital - agravada no início da década de 1970 -, que levou vários países a buscarem novas formas de organização da produção. Nesse viés, elucida-se, ainda, que o regime de acumulação flexível é caracterizado pela intensificação das inovações tecnológicas e por mudanças no mercado de trabalho, na produção e nos padrões de consumo.

Assim, o novo processo de organização da produtividade passou a exigir um trabalhador mais flexível, capaz de se adaptar às exigências do mercado de trabalho em constante mudança. $A$ educação, frente ao contexto de globalização e de produção flexível (MEDEIROS; PASSOS, 2019), passa a ser valorizada, consequentemente, como estratégia de formação de jovens para o mercado de trabalho.

Logo, observa-se que o trabalho docente em EaD carrega parte deste contexto, uma vez que presencia o surgimento de termos como "sociedade em rede", "sociedade da informação",

\footnotetext{
3 Para Medeiros e Passos (2019), o modelo de organização da produção taylorista/fordista é caracterizado pelo trabalho fragmentado, pela decomposição das tarefas e pelo controle temporal rígido nas fábricas. Comenta-se, ainda, que o fordismo se estruturou sob uma base tecnológica mecânica e eletromecânica caracterizada por rigidez e padronização de produção (FRIGOTTO, 2002). Ademais, o taylorismo/fordismo começou a mostrar sinais de esgotamento devido a uma série de fatores - como problemas ligados à rigidez do modelo organizacional -, que dificultavam a realização de mudanças, em um contexto de crise da estrutura capitalista (ANTUNES, 2009).
} 
"sociedade programada", "cibercultura" e "ciberespaço". Estes, nem sempre bem definidos, abrem, a partir do final do século XX, uma nova fase de disseminação de informação, que incide diretamente no mundo da educação e do trabalho.

Nesse contexto de revolução das tecnologias digitais, a partir de 1990, tem-se uma economia baseada no encurtamento das distâncias geográficas, na globalização e nas relações diretas entre vendedor e consumidor, intermediadas, na internet, por redes sociais e sites diversificados. Isso incide, também, no mercado educacional online, sob a visualização da oferta, em massa, de cursos; contratação de professores conteudistas para produção de materiais; excesso de alunos por tutor/docente; entre outros processos educativos ainda não estudados, que possibilitam novas reflexões, discussões e pesquisas.

\section{TRABALHO DOCENTE E EAD}

Considerando o objeto deste trabalho, primeiramente, é pertinente conceituar o termo “EaD”. Segundo Branco (2008), autores que estudam a EaD entendem-na, consensualmente, como uma modalidade de educação em que a sala de aula se dá em espaço virtual, ocasionando a nãoconvergência de encontros, em termos de espaço e tempo, entre professor/a e alunos/as.

Desse modo, os sujeitos não se encontram, face a face, todos os dias, mas utilizam de meios para que a interação aconteça. Os intermediadores, assim, podem ser plataformas virtuais de aprendizagem, vídeos, teleaulas, transmissões radiofônicas, materiais impressos, entre outros.

Nesse sentido, estudos realizados por Belloni (2006), Branco (2008; 2014) e Mill (2010) demonstram que o trabalho docente, na EaD, é exercido por vários profissionais, muitas vezes de forma fragmentada. Belloni (2006) ressalta que, ao professor, nessa modalidade de ensino, são designadas múltiplas funções. Mill (2010), ainda, denomina tais atividades por "polidocência”. Isso, pois, segundo o autor, o termo "pode ser definido como uma docência coletiva, isto é, pressupõe uma docência fragmentada em que cada parte é realizada por um trabalhador distinto" (MILL, 2010, p. $23-24)$.

Ademais, segundo Branco (2014), na educação presencial, normalmente, um único docente organiza as aulas; desenvolve o conteúdo programático; orienta os alunos nas atividades; avalia e dirige a sala. Já na educação a distância, essas responsabilidades são distribuídas entre professores conteudista e formador; designers instrucional e gráfico; administrador da plataforma; 
diagramador; tutores; entre outros atores. Há, portanto, a divisão fordista e tecnicista do trabalho, entre idealizadores - que pensam e planejam as aulas, tal qual os materiais de ensino-e executores - que colocam as tarefas premeditadas em prática, acompanhando os alunos de modo próximo.

Na perspectiva da pedagogia tecnicista, segundo Saviani (2008) e Libâneo (1986), o elemento essencial não é conteúdo, mas são as técnicas utilizadas para a aplicação desse. Os materiais manuais, livros didáticos e dispositivos audiovisuais -, nesse contexto, já trazem tópicos, atividades e respostas prontas. Não há, desse modo, espaço para reflexão, pois o conteúdo é trabalhado de forma mecânica, já que o especialista o formulou de maneira objetiva. Assim, a relação professoraluno é estrutural e planificada, com papeis bem delineados e definidos. $O$ docente administra a transmissão de conteúdos, conforme o sistema instrucional eficiente e efetivo - em termos de resultados da aprendizagem -, enquanto o discente os recebe, aprende e os internaliza.

Na perspectiva fordista, segundo Antunes (2018), o trabalho é fragmentado, parcelar, especializado e prescrito. Ao analisar as pesquisas de Branco $(2008 ; 2014)$ fica evidente como isso ocorre: há um conjunto de educadores especialistas que constroem o currículo do curso; um professor técnico que elabora os conteúdos, define as atividades e as suas possíveis respostas; e, na sequência, tutores, responsáveis por trabalhar tais âmbitos para com os alunos. Mesmo que infrequente, ainda, em alguns casos, há o contato eventual entre professor e tutor, para melhor trabalho pedagógico frente aos estudantes.

Nesse contexto, podemos entender algumas funções docentes na EaD. A Resolução no. . 1, de 11 de março de 2016, estabelece Diretrizes e Normas Nacionais para a oferta de Programas e Cursos de Educação Superior, na modalidade a distância. No Art. 8o do documento, estão expostas as seguintes distinções sobre as tarefas concernentes ao professor e ao tutor:

§ 10 Entende-se como corpo docente da instituição, na modalidade EaD, todo profissional, a ela vinculado, que atue como: autor de materiais didáticos, coordenador de curso, professor responsável por disciplina, e outras funções que envolvam o conhecimento de conteúdo, avaliação, estratégias didáticas, organização metodológica, interação e mediação pedagógica, junto aos estudantes, descritas no PDI, PPI e PPC.

$\S 2$ 을 Entende por tutor da instituição, na modalidade EaD, todo profissional de nível superior, a ela vinculado, que atue na área de conhecimento de sua formação, como suporte às atividades dos docentes e mediação pedagógica, junto a estudantes, na modalidade de EaD.

$\S$ 3으 A política de pessoal de cada IES definirá os elementos descritivos dos quadros profissionais que possui, no que concerne à caracterização, limites de atuação, regime de trabalho, atribuições, carga horária, salário, consolidado em plano de 
carreira homologado, entre outros, necessários ao desenvolvimento acadêmico na modalidade $\mathrm{EaD}$, de acordo com a legislação em vigor, respeitadas as prerrogativas de autonomia universitária e ressalvadas as peculiaridades do sistema UAB, instituído pelo Decreto n 5.800, de 2006 (BRASIL, 2016).

A Resolução (BRASIL, 2016), portanto, define ações do/a professor/a e do/a tutor/a no contexto de EaD. Ao último, ainda, recaem funções relacionadas ao suporte dos docentes e à mediação pedagógica. Neste ponto, enfatiza-se como o documento legal passa a ser contraditório, haja vista que a profissão tutor/a não é regulamentada.

Assim, a normativa estabelece a existência deste profissional, bem como lhe atribui funções docentes - isso, pois, a mediação pedagógica compõe o exercício da docência -, entretanto, não o reconhece efetivamente, frente à inexistência de representação sindical e demais entidades emblemáticas. Além disso, se esse profissional exerce funções docentes, questiona-se: faz sentido regulamentar a sua atuação como uma profissão distinta a de um/a professor/a? Ademais, pensando em consciência de classe, tão urgente na profissão, a divisão de categorias profissionais não fragmentaria as lutas do grupo?

Nesse viés, o crescente processo de individualização do trabalho acaba por romper o tecido de solidariedade e, por conseguinte, a capacidade de acionamento estratégico de coletivas de defesas. A divisão de categorias laborais na $\mathrm{EaD}$, desse modo, acaba por proporcionar o não reconhecimento desses profissionais enquanto grupo; e, nesse caso, as ações coletivas se tornam inexistentes, o que contradiz a incorporação dos trabalhadores (docentes/tutores/et al.) ao processo político de manifestação de interesses, considerando a desarticulação da solidariedade forte e intensa - entre classe/grupo. Nesse cenário, há pouca empatia ou solidariedade entre os profissionais mencionados.

Assim, para criar o compromisso para com as organizações sindicais, instrumentos de realização de interesses imediatos de nível individual ou de classe, seria necessário:

[...] a existência de um sentimento de "comunidade" partilhado por trabalhadores, definido como identidade própria, coexiste com a orientação instrumental que mapeia sua conduta social e política no ambiente de trabalho e fora dele. Este "coletivismo instrumental" não decorre primeiramente de mudanças ocorridas na estrutura ocupacional, mas de dimensões sociais e culturais mais amplas da história de vida do trabalhador, definindo o seu mapa interpretativo (PRATES, 1996, p. 4).

Ou seja, para que as organizações sindicais (trade-unions) tomem forma e tenham "poder" nas instâncias políticas, de modo que consigam "negociar" com o capital, é necessário o sentimento de pertencimento a uma classe. Este, ainda, deve levar em conta condições semelhantes de 
vivências; compartilhamentos identitários comuns e coletivos; representando e identificando outros grupos de homens e mulheres, de mesma formação social, como classe oponente. Observase, nesse contexto, que tal sensação de pertencimento, em virtude da fragmentação da área, é inexistente entre os trabalhadores da EaD:

A flexibilidade que permeia a EaD, fazendo com que os docentes atuem, por vezes, em forma de teletrabalho, acaba criando entraves quando da constituição de movimentos sindicais. [...] A forma como os trabalhadores da educação virtual se relacionam ou se organizam inviabiliza, quase que completo, toda e qualquer possibilidade de atividade sindical. E o sindicato é, para a classe trabalhadora, extremamente importante, considerando-se que, no modo de produção capitalista, abrolham-se entraves que levam à privação dos trabalhadores da melhoria de sua situação e de suas condições de trabalho (MILL; FIDALGO, 2002 apud. VELOSO, 2020, p. 104).

Por meio da fragilização dos vínculos, do trabalho em tempo parcial, da dificuldade em se constituir movimentos sindicais, do teletrabalho, da divisão das atividades, etc., a atuação docente e de tutoria na modalidade acaba se subsumindo aos interesses do capital, deixando os profissionais à mercê de variados tipos e níveis de perversidades (VELOSO, 2020).

No Brasil, presenciamos, sobretudo, um processo de precarização do trabalho formal, frente ao desmonte da legislação trabalhista. Nesse sentido, o falso discurso de se flexibilizar a Consolidação das Leis do Trabalho $(\mathrm{CLT})^{4}$, para aumentar os postos de emprego, é disseminado. Todavia, ao contrário da proposição, o que se visualiza é o aumento da exploração do trabalho e a destruição dos direitos trabalhistas, conquistados por meio das lutas da classe trabalhadora mundial, desde a Revolução Industrial, na Inglaterra. Verifica-se, ademais, não só no Brasil e não só na área educacional, o crescimento de processos de terceirização e subcontratos - os chamados empreendedorismos ou "uberização" do trabalho, que não passam de subtrabalhos informais, sem garantias de renda.

Essa realidade, assim, reflete nos contratos docentes da EaD; isso, pois, por meio das leituras realizadas, pesquisas consolidadas e da própria experiência da autora, sabe-se que a profissão de tutoria é submetida a salários baixos, inferiores aos dos professores, sem registro ou direitos trabalhistas. Nesse sentido, frisa-se que tais lacunas ocorrem justamente pela inexistência de regulamentações que abarquem a profissão.

\footnotetext{
${ }^{4}$ A Consolidação das Leis do Trabalho (CLT) é uma lei do Brasil referente ao direito do trabalho e ao direito processual do trabalho. A legislação, criada através do Decreto-Lei n.o 5 452, de 1 de maio de 1943, foi sancionada pelo, até então presidente, Getúlio Vargas, durante o período do Estado Novo, entre 1937 e 1945, e unificou toda a legislação trabalhista existente no Brasil.
} 
Voltando à questão da fragmentação da classe docente, cita-se que esta é dividida em professores de rede particular e pública; docentes da educação infantil, do ensino fundamental, médio e superior: diferenciam-se, então, os deveres, direitos e salários do professorado. Para cada nível/modalidade de ensino, há, de fato, peculiaridades; mas, pensando em consciência de classe, todos são professores: a luta para valorização profissional, formação adequada, condições apropriadas de trabalho, plano de carreira, entre outras reinvindicações precisam e devem ser unificadas.

Assim, frisa-se que, aqui, entendemos o/a tutor/a como docente. Nessa perspectiva, ao invés de lutarmos por mais uma categoria de professores, o correto não seria lutar para que esse profissional fosse reconhecido como docente e fosse valorizado como tal? A categoria tutor/a, desse modo, deixaria de existir e todos seriam identificados como professores/as, seja em contexto presencial ou a distância. Enfatiza-se isso porque a denominação "tutor/a" tem chegado aos cursos presenciais, precarizando a atuação docente também in loco.

Sem a devida regulamentação ou com a precarização desta, esses trabalhadores passam a exercer atividades informais e, às vezes, recebem, inclusive, outras denominações, como "monitores". Nesse sentido, combinam, ainda, outras atividades laborais com a tutoria, deixando esta última em segundo plano, devido à remuneração recebida.

No contexto de múltiplas funções acumuladas, Antunes (2018) define a atividade com menor remuneração como "bicos". Podemos concordar, ou não, com o autor: se pensarmos que ganhos financeiros, advindos dessa outra atividade, são essenciais para a composição salarial e que, durante o trabalho "extra", há, também, a melhoria na formação do profissional e nas suas experiências docentes, em termos de incremento curricular, o ofício passa a ser, tal qual o "primeiro", imprescindível na vida do/a trabalhador/a.

O momento político e econômico do atual do país, com taxas elevadas de desemprego, baixos salários e crescimento vertiginoso do trabalho informal, face à classe abordada, também nos faz repensar a realidade do "bico" e do trabalho "principal". Isso ocorre, segundo Antunes (2015), porque há um amplo contingente de força humana disponível para o trabalho, em escala global. Nesse sentido, verifica-se que tal mão de obra vem realizando trabalhos temporários, precarizados, instáveis e terceirizados, em diversos segmentos, inclusive na área educacional. 


\section{PROFESSORES/AS E TUTORES/AS: O REGIME DE TRABALHO NO SISTEMA UNIVERSIDADE ABERTA DO BRASIL}

Como política destinada à formação docente e com a possibilidade de se atingir um grande contingente de participantes, o Governo Federal, em 2006, por meio do Decreto № 5.800, de 8 de junho de 2006 (BRASIL, 2006), instituiu o Sistema de ensino Universidade Aberta do Brasil (UAB) ${ }^{5}$, com a finalidade de expandir e interiorizar a oferta de cursos e programas de educação superior no país. Para Branco e Peixoto (2018a), "o termo Universidade Aberta é utilizado para descrever sistemas flexíveis de ensino, geralmente desenvolvidos para atender demandas específicas" ( $p$. 667). Essa definição, portanto, é consonante ao conceito de EaD, uma vez que os sujeitos envolvidos no processo de ensino-aprendizagem, em ambos os contextos, têm flexibilidade de tempo e espaço, para organização e realização de suas respectivas atividades.

Todavia, segundo Mill (2012), por meio do Decreto citado, não se criou uma nova instituição de ensino superior, mas se realizou a articulação das instituições públicas, já existentes, para um cenário educativo relativamente flexível. Por isso, a denominação de "sistema" UAB, não "instituição" universitária.

O funcionamento da organização, em síntese, dá-se através da mobilização e responsabilização de municípios e estados pela infraestrutura de pólos de apoio presencial - que recebem os alunos e realizam encontros presenciais com auxílio de tutores/as e professores/as. As universidades, nesse contexto, são autonomamente responsáveis pela parte pedagógica dos cursos: organizam os currículos; estruturam a coordenação e os colegiados; sistematizam e definem conteúdos e avaliações; bem como formulam o mediador através do qual a interação de todos os envolvidos se dará. Importante dizer, ainda, que "toda instituição de ensino, independentemente de sua organização acadêmica ou natureza administrativa, precisa estar credenciada pelo Poder Público, para que possa atuar na educação superior do país" (NOGUEIRA; NUNES; BARROSO, 2011, p. 3).

\footnotetext{
${ }^{5}$ A Universidade Aberta do Brasil, como política pública federal, é um sistema integrado, que envolve universidades públicas (municipais e estaduais). A medida, ainda, oferece cursos a diversos níveis de ensino - sobretudo em nível superior -, por meio da metodologia da educação a distância.
} 
A pesquisa realizada para elaboração deste texto demonstrou que, em primeiro momento de regulamentação da modalidade de ensino, foi a promulgada a Lei no 4.024, de 20 de dezembro de 1961 (BRASIL, 1961), que fixou as Diretrizes e Bases da Educação Nacional e introduziu regulamentações para esse processo. Entretanto, somente em 1996, com a Lei de Diretrizes e Bases da Educação Nacional atual - a LDBEN 9394/1996 -, que o termo “Credenciamento de Instituições de Ensino Superior para Educação a Distância" apareceu, na legislação brasileira, de modo destacado. Sobre isso, Branco e Peixoto afirmam:

A LDBEN 9394/96 estabelece que a União, os estados e os municípios serão responsáveis pelo credenciamento de instituições de ensino superior, sendo cada um responsável pelo seu sistema de ensino. No Art. 46 ressalta que esse credenciamento tem prazo limitado, devendo ser renovado periodicamente, a partir de processo regular de avaliação. $O$ credenciamento de instituições para a oferta da educação a distância é específico e feito apenas pela União (BRANCO; PEIXOTO, 2018b, p. 132).

Nesse sentido, o Decreto no 9.057, de 25 de maio de 2017, expõe que o Ministério da Educação continua sendo o órgão responsável por credenciar e recredenciar as instituições de ensino superior para a oferta de cursos de graduação a distância; sendo tal licença permitida exclusivamente para oferta de trajetórias de graduação e de pós-graduação lato sensu, na modalidade a distância. Além disso, os centros públicos de educação universitária, mesmo não credenciados para tal oferta, o estão automaticamente - haja vista que, somente após cinco anos do primeiro curso ofertado, é que passarão pelo processo de recredenciamento; para, então, serem avaliados de acordo com os procedimentos legais preestabelecidos e demais definições.

Especificamente sobre o trabalho de tutoria na UAB, Oliveira e Lima (2013) e Brito e Costa (2013) definem essa atividade como docência e enfatizam que as condições de atuação profissional são precárias, uma vez que a função é pouco reconhecida quanto ao seu papel fundamental para a execução dos cursos a distância da UAB. Isso, pois, no cotidiano dos cursos, este profissional acompanha os alunos, orienta o conhecimento e cria situações de aprendizagem.

Em conformidade aos autores anteriormente citados, os dados da pesquisa de Mill (2006), sobre a atuação laboral, evidenciam que, geralmente, o/a tutor/a tem grande volume de alunos; recebe bolsas de pequeno valor monetário; é muito cobrado pela equipe pedagógica; e corrige um grande volume de atividades em um tempo controlado pelo Ambiente Virtual de Aprendizagem (AVA). Ao profissional, ainda, são exigidas competências e características diversas, como a abertura ao novo; adaptabilidade; capacidade de gestão e autogestão; carisma; colaboração; crença na EaD; 
caráter multiplicador; praticidade; responsabilidade; tolerância; perfil trabalhador; dentre outras. Enquanto isso, a equipe de tutoria da $U A B$, por exemplo, recebe uma bolsa no valor de $\mathrm{R} \$ 765,00$.

Ademais, os resultados obtidos na pesquisa in loco de Branco (2014) demonstram que o tutor acompanha os alunos no AVA, participa dos fóruns, tira dúvidas virtualmente, além de verificar a entrada, a saída e a participação dos estudantes nesse mesmo ambiente. O referido profissional, também, observa o desenvolvimento das habilidades dos alunos no uso da plataforma, bem como discute, nesse local, junto aos discentes, os conteúdos ministrados. Há, também, tutores/as que trabalham em pólos de apoio presencial e que realizam o atendimento dos/as discentes: auxiliam em questões burocráticas e acadêmicas; fornecem informações gerais sobre o curso; tiram dúvidas sobre o conteúdo; aplicam provas; e organizam videoconferências.

Para Zuin (2006), portanto, esse profissional desempenha um papel imprescindível, não devendo apenas absorver os conhecimentos e os conteúdos do curso e repassá-los aos estudantes. Ele deve ousar, questionar os conhecimentos e debater com discentes, instigando a reflexão e o questionamento.

Finalmente, o estudo bibliográfico e documental realizado, bem como a experiência da autora deste texto, evidenciam que o trabalho de tutoria é exigente e pouco valorizado. 0 profissional tutor, desse modo, além de ser um/a educador/a - pois é uma referência para os/as alunos/as -, precisa entender sobre a gestão e a organização do curso, uma vez que ele/a é a ligação entre discentes, docentes, coordenação do curso e instituição ofertante. Nesse sentido, verifica-se, também, que a valorização não monetária deste profissional ocorre, no geral, em virtude da falta respeito dos/as estudantes para com o trabalho de tutoria.

\section{TECENDO CONSIDERAÇÕES}

Mesmo diante de tantos desafios, a modalidade EaD pode ser percebida como um processo educativo que se relaciona, diretamente, à redução das desigualdades e ao acesso ao conhecimento por aprendizes que, sob outras circunstâncias, estariam isolados. Assim, compreende-se que as ofertas da EaD, por meio das tecnologias digitais, começam a superar não só os limites geográficos internos, mas nacionais. Verifica-se, nesse sentido, que o modelo de ensino pode constituir uma 
oportunidade de formação para pessoas que, por alguma razão, possuem dificuldades ou impossibilidades de acessarem as instituições convencionais de educação (MILL; VELOSO, 2018).

Porém, com o advento e com a expansão dos novos trabalhos relativos (mais ou menos intermitentes; mais ou menos constantes) - que ganharam impulso com as TICs -, presenciamos o crescimento do proletariado de serviços (uma variante global do que se pode denominar, sem exageros, em pleno século XXI (ANTUNES, 2018), “escravidão digital”). Nesse contexto, há o aumento, no setor laboral, da contratação de professores-tutores, que atuam a distância, com salários menores, jornadas prolongadas (se comparada aos profissionais da educação presencial) e sob a "burla" da legislação social (protetora do trabalho).

Desse modo, ainda que a oferta de cursos a distância, no sistema UAB, seja significativamente ampliado, economiza-se na remuneração e na organização do trabalho docente/tutor, o que também compromete a qualidade do processo de ensino-aprendizagem oferecido. Isso, pois, no Brasil, em contexto de EaD, a realidade vivida pelas Instituições de Ensino Superior (IES) públicas é de que a modalidade de ensino ainda não possui a institucionalização desejada; visto que as IES públicas ofertam cursos a distância por meio de programas, enquanto o pagamento dos profissionais envolvidos é realizado através de bolsas.

Todavia, mesmo com tais impasses, podemos acreditar na possibilidade de democratização da educação via EaD; na construção de redes de inteligência coletiva via cibercultura/ciberespaço; e em políticas públicas que enfoquem o bem social - por meio da disseminação de "softwares livres", por exemplo -, e oportunidades educacionais justas. Entretanto, o que presenciamos, na maioria dos cenários, é privatização das redes, interesse neoliberal na propagação do ensino e restrição de acesso aos meios.

Nesse contexto, quando analisamos as condições objetivas de trabalho dos docentes da EaD, percebemos que o lucro sobrepõe a qualidade, nas instituições privadas; e que, nas instituições públicas, não há o investimento devido na modalidade, se compararmos aos recursos atribuídos à educação presencial. Junto a isso, os problemas de acesso aos equipamentos digitais e à rede de internet, pela maioria da população, são factíveis. Ademais, frente à pandemia instaurada pela COVID-19, verifica-se que tais aspectos são evidenciados, uma vez que os centros educacionais públicos e privados tentam impor ações de educação a distância sem a qualidade devida, formação docente necessária, infra-estrutura adequada, tempo de preparação e/ou discussão de cenários e possibilidades; tudo é, portanto, feito "a toque de caixa" (comum, no país, na área educacional). 
Assim, como mencionado anteriormente, a atuação laboral realizada a distância gera a "flexibilização"; que, consequentemente, promove, na EaD, a precarização da atividade docente e de tutores. Fragilização, ainda, porque muitos profissionais dessa modalidade acumulam suas funções e outras atividades remuneradas para a complementação de seu salário, gerando contratos de trabalho precários, sem a segurança trabalhista legal.

Ademais, a expansão dos cursos a distância, especialmente em instituições privadas, tem massificado o ensino de forma a torná-lo, efetivamente, aquilo que podemos pejorativamente intitular "fábrica de diplomas". Em meio a esse processo industrial, o profissional docente, tão importante às várias propostas de ensino-aprendizagem, encontra-se envolvido em diversas situações de precarização do trabalho. Vê-se, assim, uma clara exploração que se desdobra em diferentes problemáticas: fragilização de vínculos, salários precários, sobrecarga nas atividades, dentre outras (VELOSO, 2020, p. 106).

Finalmente, cabe ressaltar que o debate tecido neste texto vê as experiências em EaD como diversas, amplas e múltiplas; sendo que, apesar das complexidades intrínsecas a tais vivências, estas também são positivas (principalmente a possibilidade de extensão geográfica do conhecimento acadêmico/escolar). Nesse sentido, chama-se a atenção para a precariedade do trabalho docente e de tutoria, que envolvem aspectos perversos de contratação (mediante bolsa) - isto é, a fragilização ou inexistência de vínculos empregatícios -, além da sobrecarga de trabalho. Tal situação, ainda, tem relação direta ao padrão da educação ofertada; portanto, é necessário que se repense a "flexibilização" dos trabalhos em EaD, a fim de manter uma docência comprometida e, consequentemente, um processo de ensino-aprendizagem de qualidade.

\section{REFERÊNCIAS}

ANTUNES, Ricardo. Adeus ao trabalho?: ensaio sobre as metamorfoses e a centralidade do mundo do trabalho. 16 ed. São Paulo: Cortez, 2015.

ANTUNES, Ricardo. O privilégio da servidão: o novo proletariado de serviço na era digital. São Paulo: Boitempo, 2018.

ANTUNES, Ricardo. Os sentidos do trabalho: ensaio sobre a afirmação e a negação do trabalho. 2 ed. São Paulo: Boitempo, 2009.

BARRETO, Hugo. Aprendizagem por televisão. In: LITTO, Frederic Michael; FORMIGA, Manuel Marcos Maciel (Orgs.). Educação a distância: o estado da arte. São Paulo: Person Education do Brasil, 2009. 
BELLONI, Maria Luiza. Educação a distância. 4 ed. Campinas: Autores Associados. 2006.

BIANCO, Nelia R. Del. Aprendizagem por rádio. In: LITTO, Frederic Michael; FORMIGA, Manuel Marcos Maciel (Orgs.). Educação a distância: o estado da arte. São Paulo: Person Education do Brasil, 2009.

BRANCO, Juliana Cordeiro Soares. A educação a distância para o professor em serviço. 2008. 193 f. Dissertação (Mestrado em Educação) - Centro Federal de Educação Tecnológica de Minas Gerais, Belo Horizonte, 2008.

BRANCO, Juliana Cordeiro Soares. A formação de professores a distância no Sistema UAB: análise de duas experiências em Minas Gerais. 2014. Tese (Doutorado em Educação) - Faculdade de Educação, Universidade Federal de Minas Gerais, Belo Horizonte, 2014. Disponível em: <http://www.bibliotecadigital.ufmg.br/dspace/bitstream/handle/1843/BUOS9N7GEA/tese juliana branco vers o final 26 06.pdf? sequence=1>.

BRANCO, Juliana Cordeiro Soares; PEIXOTO, Maria do Carmo de Lacerda. Credenciamento de Instituições de Ensino Superior para Educação a Distância. In: MILL, Daniel Ribeiro Silva (Org.). Dicionário crítico de educação e tecnologias e de educação a distância. Campinas: Papirus, 2018b.

BRANCO, Juliana Cordeiro Soares; PEIXOTO, Maria do Carmo de Lacerda. Sistema Universidade Aberta do Brasil. In: MILL, Daniel Ribeiro Silva (Org.). Dicionário crítico de educação e tecnologias e de educação a distância. Campinas: Papirus, 2018a.

BRASIL. Lei no 4.024, de 20 de dezembro de 1961. Fixa as Diretrizes e Bases da Educação Nacional. Diário Oficial da República Federativa do Brasil, Brasília, DF, 20 dez. 1961.

BRASIL. Resolução CNE/CES no 1, de 11 de março de 2016. Define as Diretrizes e Normas Nacionais para a Oferta de Programas e Cursos de Educação Superior na Modalidade a Distância. Conselho Nacional de Educação - Diário Oficial da República Federativa do Brasil, Brasília, DF, 11 mar. 2016.

BRITO, Glaucia da Silva; COSTA, Maria Luisa Furlan. O processo de seleção do tutor na Universidade Aberta do Brasil UAB: reflexões necessárias. In: Congresso brasileiro de Ensino Superior a Distância. Belém: UFPA, 2013, v. 10. Disponível em:

<http://www.aedi.ufpa.br/esud/trabalhos-oral.html>.

CASTELLS, Manuel. A sociedade em Rede: a era da informação, economia, sociedade e cultura. v. 1. 6 ed. Tradução de Roneide Venancio Majer. São Paulo: Paz \& Terra, 2011.

FORMIGA, Manuel Marcos Maciel. A terminologia da EAD. In: LITTO, Frederic Michael; FORMIGA, Manuel Marcos Maciel (Orgs.). Educação a distância: o estado da arte. São Paulo: Person.

FRIGOTTO, Gaudêncio. Educação e formação humana: ajuste neoconservador e alternativa democrática. In: GENTILI, Pablo A.; SILVA, Tomaz T. da. Neoliberalismo, qualidade total e educação. 11 ed. Petrópolis: Editora Vozes, 2002.

GOUVÊA, Guaracira; OLIVEIRA, Carmen Irene. Educação a distância na formação de professores. Rio de Janeiro: Vieira e Lent, 2006.

LIBÂNEO, José C. A democratização da escola pública: a pedagogia crítico-social dos conteúdos. 4 ed. São Paulo: Loyola, 1986. 
MEDEIROS, Tatiane Cimara dos Santos; PASSOS, Daniela Oliveira Ramos dos. Reformas do Ensino Médio e trabalhista: possíveis implicações para educação profissional técnica de nível médio.

Revista Trabalho Necessário, v. 17, n. 34, set.-dez./2019. Disponível em:

<https://periodicos.uff.br/trabalhonecessario/article/view/38054/21781>.

MILL, Daniel Ribeiro Silva. A Universidade Aberta do Brasil. In: LITTO, Frederic Michael; FORMIGA, Manuel Marcos Maciel (Orgs.). Educação a distância: o estado da arte. v. 2. São Paulo: Person Education do Brasil, 2012.

MILL, Daniel Ribeiro Silva. Educação a distância e trabalho docente virtual: sobre tecnologia, espaços, tempos, coletividade e relações sociais de sexo na Idade Mídia. 2006. Tese (Doutorado em Educação) - Faculdade de Educação, Universidade Federal de Minas Gerais, Belo Horizonte, 2006.

MILL, Daniel Ribeiro Silva. Sobre o conceito de polidocência ou sobre a natureza do processo de trabalho pedagógico na Educação a distância. In: MILL, Daniel Ribeiro Silva; RIBEIRO, Luis Roberto de Camargo; OLIVEIRA, Marcia Rozenfeld Gomes de (Orgs.). Polidocência na educação a distância: múltiplos enfoques. São Carlos: EdUFSCAR, 2010.

MILL, Daniel Ribeiro Silva; VELOSO, Braian. Precarização do trabalho docente na educação a distância: uma análise sobre o sistema Universidade Aberta do Brasil. In: Congresso Internacional de Educação e Tecnologias / Encontro de Pesquisadores em Educação à Distância. São Carlos: UFSCar, 2018.

NOGUEIRA, André Magalhães; NUNES, Edson; BARROSO, Helena Maria. A origem do credenciamento: autorização e reconhecimento de universidades. Documentos de Trabalho, $n$. 96, Rio de Janeiro, jun./2011. Disponível em:

$<$ http://www.observatoriouniversitario.org.br/documentos de trabalho/documentos de trabalh o $96 . p d f>$.

NUNES, Ivônio Barros. A história da EaD no mundo. In: LITTO, Frederic Michael; FORMIGA, Manuel Marcos Maciel (Orgs.). Educação a distância: o estado da arte. São Paulo: Person Education do Brasil, 2009.

OLIVEIRA, Francisnaine Priscila Martins de; LIMA, Claudia Maria de. O tutor dos cursos de pedagogia das instituições de ensino superior parceiras da Universidade Aberta do Brasil: aspectos da profissionalização. In: Congresso brasileiro de Ensino Superior a Distância. Belém: UFPA, 2013, v. 10. Disponível em: <http://www.aedi.ufpa.br/esud/trabalhos-oral.html>.

PALHARES, Roberto. Aprendizagem por correspondência. In: LITTO, Frederic Michael; FORMIGA, Manuel Marcos Maciel (Orgs.). Educação a distância: o estado da arte. São Paulo: Person Education do Brasil, 2009.

PETERS, Otto. Didática do ensino a distância: Experiências e estágio da discussão numa visão internacional. Tradução de Ilson Kayser. São Leopoldo: Unisinos, 2006.

PRATES, Antônio Augusto Pereira. Sindicato: Organização e Interesses na Sociedade Capitalista Avançada. In: Revista Brasileira de Ciências Sociais, n. 2, out./1996.

SARAIVA, Terezinha. Educação a distância no Brasil: lições de história. Em aberto, ano 16, n. 70, p. 17-27, abr.-jun./1996. 
SAVIANI, Dermeval. Escola e Democracia. Edição Comemorativa. Campinas: Autores Associados, 2008.

VELOSO, Braian. Trabalho docente na educação a distância: uma abordagem crítica In: VELOSO, Braian; SILVEIRA, Claudia Alexandra Bolela; LOPES, Mario Marcos (Orgs.). Educação e Tecnologias em Debate: perspectivas sob diferentes áreas do conhecimento. São Carlos: Pedro \& João Editores, 2020, p. 97-114.

ZUIN, Antonio A. S. Educação a distância ou educação distante? O Programa Universidade Aberta do Brasil, o tutor e o professor virtual. Educ. Soc., v. 27, n. 96, out./2006.

\section{SOBRE AS AUTORAS}

\section{Juliana Cordeiro Soares Branco}

Doutorado em Educação, Faculdade de Educação, UFMG; Docente na Faculdade de Educação da UEMG, Belo Horizonte, Brasil; e do Programa Pós-Graduação Stricto Sensu em Educação - Mestrado Acadêmico em Educação e Formação Humana - da Faculdade de Educação da Universidade do Estado de Minas Gerais (FaE/UEMG); Coordenadora do Núcleo de Estudos e Pesquisas em Educação, Comunicação e Tecnologia (NECT) e integrante do Núcleo de Pesquisa em Políticas Públicas Educacionais (NEPPPE).

E-mail: juliana.branco@uemg.br

ORCID: https://orcid.org/0000-0003-2337-2918

\section{Daniela Oliveira Ramos dos Passos}

Doutora em Sociologia pela Universidade Federal de Minas Gerais, UFMG. Docente na Faculdade de Educação da Universidade do Estado de Minas Gerais, UEMG. Professora do quadro permanente do Programa Pós-Graduação Stricto Sensu em Educação - Mestrado Acadêmico em Educação e Formação Humana - da Faculdade de Educação da Universidade do Estado de Minas Gerais (FaE/UEMG). Integrante dos Núcleos de Estudos e Pesquisas em Educação, Sociologia e Filosofia (NEPESF) e em História da Educação (NEPHE).

E-mail: daniela.passos@uemg.br

ORCID: https://orcid.org/0000-0002-3087-0694

Recebido em: $14 / 08 / 2020$

Aprovado em: 08/12/2020

Publicado em: 14/12/2020 